\title{
Feminismo brasileiro como luta e epistemologia
}

\author{
[ Brazilian feminism as a struggle and epistemology
}

\section{Gleyce Kelly Heitor ${ }^{\mathrm{I}}$}

BUARQUE DE HOLLANDA, Heloisa (org.). Pensamento feminista brasileiro: formação e contexto. Rio de Janeiro: Bazar do Tempo, 20I9. 400 p.

RESUMO - Pensamento feminista brasileiro: formação e contexto foi organizado por Heloisa Buarque de Hollanda no intuito de oferecer referências e repertórios para a atual geração de pesquisadoras, pesquisadores e ativistas que se identificam com a pesquisa e a luta feminista. Soma-se a uma série de outros livros, de sua autoria, nos quais os debates nacionais e internacionais - históricos e emergentes - são mapeados, pondo em relação os diálogos e os esforços por legitimação dos estudos sobre as mulheres e sua dimensão epistemológica. Neste texto apresentaremos alguns aspectos do livro, acentuando como as escolhas da autora são justificadas e entrecortadas pelo ambiente de (auto)formação que caracteriza o seu encontro e agência frente ao desenvolvimento e difusão desse pensamento. • PALAVRASCHAVE - Feminismo; estudos de gênero; Heloisa Buarque de Hollanda. • ABSTRACT
- "Brazilian feminist thought: constitution and context" was organized by Heloisa Buarque de Hollanda, with the intention of offering references and repertoires for the current generation of researchers and activists identified with feminist research and struggle. Adding up to a series of other books, that she wrote, in which national and international debates - historical and emergent - are mapped out, bringing together the dialogues and efforts to legitimize studies on women and their epistemological dimension. In this text we will present some aspects of the book, emphasizing how the author's choices are justified and interrupted by the (self) formation environment that characterizes her encounter and action in the face of the development and diffusion of the feminist thought. · KEYWORDS - Feminism; gender studies; Heloisa Buarque de Hollanda.

Recebido em I5 de setembro de 2020

Aprovado em II de novembro de 2020

HEITOR, Gleyce Kelly. Feminismo brasileiro como luta e epistemologia. Revista do Instituto de Estudos Brasileiros, Brasil, n. 77, p. 2II-2I8, dez. 2020.

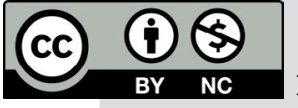

DOI: https://doi.org/Io.II6o6/issn.23I6-9oIX.vIi77p2II-2I8

I Pontifícia Universidade Católica do Rio de Janeiro (PUC-Rio, Rio de Janeiro, RJ, Brasil). 
Como o pensamento feminista se formou no Brasil? Quais foram os objetos, as principais bases teóricas e os desafios metodológicos enfrentados pelas pesquisadoras que ousaram fazer de temas como gênero, violência doméstica, trabalho, corpo e sexualidade feminina questões para suas pesquisas acadêmicas, inserindo, portanto, no ambiente público da universidade assuntos que foram historicamente relegados à esfera privada? O que foi necessário para que suas posições, entre militância e reflexão, mais do que institucionalizadas, não fossem deslegitimadas pelos pares - que reproduzem, no contexto acadêmico, a lógica do "sistema mundo colonial/patriarcal” (GROSFOGUEL, 2005 - tradução minha)? O que conhecemos e como produzimos memória e arquivo em torno desses pensamentos, trajetórias e pioneirismos? Essas são questões que povoam o livro Pensamento feminista brasileiro: formação e contexto, organizado por Heloisa Buarque de Hollanda.

A coletânea conflui com as comemorações do $80^{\circ}$ aniversário de sua organizadora e foi precedida por Explosão feminista: arte, cultura, política e universidade (HOLLANDA, 20I8), livro no qual estão reunidas mulheres de diferentes contextos e gerações, possibilitando a quem lê o texto um mapeamento, a partir do recorte que o próprio título do livro demarca, das emergências que constituem o pensamento feminista na atualidade, dando a ver tanto posições que se interseccionam como os antagonismos que explicitam não haver um feminismo homogêneo. No último capítulo desse livro, intitulado "As veteranas ou um sinal de alerta sobre uma memória não escrita", Heloisa Buarque de Hollanda (20I3) aponta para uma lacuna: havia, no Brasil, uma história do feminismo que ainda precisava ser contada - melhor dizendo, desarquivada ${ }^{2}$.

Se, por um lado, a nova geração de pensadoras feministas se singulariza pelo vigor e por um tipo de consciência que as distingue das antecedentes - inclusive pelo fato de serem formadas e informadas tendo a internet como lócus privilegiado para trocas, articulações e mobilizações -, era importante, para a autora, que essa mesma geração adquirisse repertório do ponto de vista tanto histórico, como conceitual. Que pudessem acessar o caminho percorrido por mulheres como Bila Sorj, Sueli

2 “Desarquivo", como proposto por A Arquivista e Cristina Ribas (20I4, p. 27), é "a incitação de tirar algo do lugar de maneira a mobilizar e colocar em relação". 
Carneiro, Jacqueline Pitanguy, Malu Heilborn, Schuma Schumaher, Maria Betânia Ávila, Branca Moreira Alves.

Essa lacuna, Heloísa Buarque de Hollanda buscou suprir com a organização da coleção Pensamento Feminista, formada por dois livros, nos quais ela visita e revisita as bases desse pensamento, a partir de um movimento que vai do internacional ao nacional, do histórico ao emergente, para oferecer os panoramas, os diálogos e os esforços por legitimação dos estudos de gênero, assim como o reconhecimento da sua dimensão epistemológica.

Pensamento feminista: conceitos fundamentais (HOLLANDA, 20I8), primeira obra da coleção, é apresentado pela autora como um curso, reúne importantes vozes do feminismo e tem como marco as primeiras ocorrências da ideia de gênero, seus usos e conceituações, cujas reflexões são marcadas pelo pensamento de Nancy Fraser e Joan Scott, abarcando ainda a mudança de paradigmas que tensionam o gênero como categoria, cujo principal representante - e voz -, nesse livro, é Paul Preciado.

Nesse sentido, é importante remarcar que Pensamento feminista brasileiro: formação e contexto não pode ser visto como um trabalho isolado. Como aponta o título, o livro dedica-se às pioneiras na formação do pensamento feminista no Brasil, com recorte para o lugar desse pensamento no contexto acadêmico, sendo composto de ensaios, artigos e palestras de autoras como Sueli Carneiro e Lélia Gonzales, e ainda de Heleieth Saffioti, Maria Betânia Ávila, Jacqueline Pitanguy, Branca Moreira Alves, Constância Lima Duarte, pessoas que ajudaram a construir essa história - antes e junto com Heloisa.

Pensados em conjunto, esses três livros cumprem uma função que sua organizadora considera primordial: fornecer repertório - histórico, conceitual e epistemológico - para as novas gerações de ativistas, pesquisadoras e pensadoras do feminismo. Nesse sentido, ao revisitar sua biblioteca e selecionar o que considera relevante, seminal e passível de ser legado, ela reescreve também seu processo de formação como mulher, pesquisadora e feminista, visibilizando como alguns dos enfretamentos coletivos analisados pelos artigos compilados nesses livros formam também o conjunto de embates enfrentados por ela ao longo de sua trajetória.

Heloisa Buarque de Hollanda, ensaísta, escritora, editora e crítica cultural, nasceu em Ribeirão Preto (SP), em I939. Como percurso acadêmico, graduou-se em Letras Clássicas pela Pontifícia Universidade Católica do Rio de Janeiro (PUC-Rio), concluiu mestrado e doutorado em Literatura Brasileira pela Universidade Federal do Rio de Janeiro (UFRJ), onde é atualmente professora emérita de Teoria da Cultura da Escola de Comunicação e onde coordena, como parte do Programa Avançado de Cultura Contemporânea, a Universidade das Quebradas, projeto voltado para a formação de artistas, ativistas e produtores culturais atuantes nas periferias do Rio de Janeiro. Seu percurso é marcado pela relação com temas como poesia, relações de gênero e étnicas, culturas marginalizadas e cultura digital. 


\section{EU QUERIA BOTAR FOGO NO APARTAMENTO}

Essa é a resposta da autora (HOLANDA, 20I3) - parafraseando a célebre música - para uma pergunta sobre quem era ela, no ambiente político e social de I968, ano que foi marcado internacionalmente por uma virada do ponto de vista dos costumes, encabeçada por diferentes movimentos políticos e culturais, cujas reivindicações punham em questão a hegemonia de instituições e estruturas como a igreja, a universidade, o estado, a família e mesmo a cultura. No Brasil, por sua vez, I968 é lembrado como o momento da publicação do Ato Institucional n. 5, pelo governo do general Costa e Silva, marcando uma década de recrudescimento da ditadura civil-militar na qual os governantes tinham poder de exceção para punir arbitrariamente todas as oposições ao regime.

Correr mundo, correr perigo como metáforas para a desejada ruptura com a ordem vigente são desejos expressos pelo narrador, na música "Você não entende nada”, lançada por Caetano Veloso, em I97I Música que dialoga com outra canção, hoje lida como uma crônica na qual vemos traduzido o contexto cultural e social dessa época e geração, que é "Cotidiano", composta por Chico Buarque em I97I, e que fez parte da trilha sonora da telenovela Como salvar meu casamento, que foi ao ar pela TV Tupi em I979, no horário nobre das 2oh.

O que essas canções têm em comum? Elas partilham, literalmente, a descrição do cotidiano de uma mulher, narrado por um eu lírico masculino, e fazem emergir o sentimento de tédio e de frustração - dos homens - com a rotina que marca o ambiente doméstico, seus afazeres e demandas. Corroboram a imagem da mulher domesticada, colonizada e marcada pelo que Silvia Federici (20I7, p. 3I) analisou como "função-trabalho", que é a atribuição às mulheres de um conjunto de práticas ligadas ao cuidado - que no caso das duas músicas se traduz, inclusive, como a obrigação pela manutenção do desejo. Ambas apresentam as mulheres no ambiente privado, da casa, do lar, do apartamento, à medida que os homens circulam, observam, atuam e vislumbram seu movimento tendo como base o exterior, o espaço público, a amplitude do mundo.

Ao se apropriar do desejo/agência desse eu lírico, Heloisa Buarque de Hollanda descreve, por sua vez, o seu estado de espírito e a sensação de desajuste e descontentamento compartilhado com outras mulheres pertencentes a sua geração, classe e círculo sociocultural, para as quais a ruptura com as estruturas familiares e domésticas - ou, como aconselhou Virginia Wolf (20I2, p. II), a possibilidade de "matar o anjo do lar" - era condição de possibilidade para o surgimento de um conjunto de reflexões, inquietações e um agir político no mundo que no livro será analisado como pensamento feminista. 


\section{SOMOS FALAS, TEMOS FALANGES ${ }^{3}$}

Sem responder a padrões cronológicos lineares, Pensamento feminista brasileiro: formação e contexto tem 398 páginas distribuídas entre introdução e quatro seções, com artigos e ensaios sistematizados a partir de temas comuns, buscando contemplar histórias, bandeiras e reivindicações, a ideia de pioneirismo a partir de um recorte racial e interseccional e os aspectos epistemológicos do feminismo como área de estudos. Burca também oferecer chaves de leitura que corroborem o combate contra a "colonização teórica" (p. 9) presente nas disciplinas acadêmicas, com bibliografias predominantemente europeia e norte-americana.

Na introdução, as escolhas da organizadora são justificadas e entrecortadas à medida que o seu ambiente de (auto)formação é descortinado e passado em retrospecto, enfatizando seu encontro com esse pensamento que, segundo o marco temporal do livro, emerge no Brasil na década de I970 a partir da circulação de textos e ideias oriundos de diferentes circuitos internacionais, pelos grupos de leitura compostos de mulheres, vinculadas à academia e aos movimentos sociais. Pode-se dizer, a partir desse relato, que a formação das teorias feministas no país reflete um movimento mundial das lutas das mulheres por direitos civis. No Brasil, no entanto, várias dessas agendas, como direitos reprodutivos, liberdade e igualdade sexual, divórcio, dentre outras, foram suplantadas pela luta contra a ditadura militar e contra a censura, e silenciadas pela urgência de pautas mais amplas, como a luta de classes e os movimentos pela redemocratização do país, pela anistia e contra as desigualdades sociais.

A autora aprofunda sua relação com o feminismo, no entanto, fora do Brasil, durante o pós-doutorado em Sociologia da Cultura, realizado na University of Columbia, no início da década de I980. Nesse contexto, vai entrar em contato com o panorama diverso e efervescente do feminismo norte-americano, em que temas e cânones como o marxismo, a psicanálise freudiana e a religião vinham sendo relidos e problematizados desde uma perspectiva de gênero, sendo também nessa ocasião e contexto que as agendas do feminismo negro e latino, bem como as singularidades dessas experiências, começaram a pautar a necessidade do agenciamento de outras vozes como contraponto à predominância do feminismo branco e acadêmico. Segundo ela, a "luta contra a discriminação sexual e racial no acesso e na vida acadêmica, a organização profissional nas universidades, a composição do cânone teórico e literário, o conservadorismo dos fundamentos das ciências sociais são pautas de primeira grandeza nesse contexto do feminismo acadêmico dos anos I960-70” (p. II).

Ainda na introdução, nos confrontamos com os principais desafios encontrados por essa geração na afirmação do feminismo, seja como movimento político, seja como campo para as pesquisas acadêmicas: a ênfase dos diferentes movimentos de esquerda em pautas mais amplas, como a já citada redemocratização, a conflituosa negociação com a igreja, que apoiava a luta das mulheres, sobretudo com aderência a pautas como desigualdade, sem que houvesse, contudo, espaço para debates em torno das sexualidades, dos direitos reprodutivos, do aborto ou do divórcio, e, no

3 Trecho de manifesto em homenagem ao Dia das Mulheres (SLAM DAS MINAS, 20I8). 
âmbito acadêmico, o enfrentamento com os cânones e com o androcentrismo nas diferentes áreas do conhecimento. Esses são alguns dos temas que levaram tanto as militantes como as intelectuais desse alvorecer dos estudos de gênero e sobre mulheres no Brasil ora a recuar, ora a avançar no fortalecimento do lugar político e epistemológico dessas reflexões na sociedade.

"Algumas histórias sobre o feminismo no Brasil", primeira seção do livro, conta com seis textos ali dispostos no intuito de "organizar a história do feminismo no Brasil" (p. I6). História que, por esse recorte, é demarcada pela luta por direitos civis, pela participação das mulheres na constituinte, pelo papel das escritoras nos debates e embates presentes na constituição da identidade nacional. Sendo relevante destacar que, para além dos aspectos factuais dessas narrativas, Bila Sorj vai pensar a história do feminismo a partir do debate em torno das temporalidades modernas e pós-modernas, bem como nas que cada um desses recortes temporais implica nas análises do tema.

Destaca-se, ainda, nessa seção, o artigo "Feminismo, uma história a ser contada" (2003), no qual Constância Lima Duarte realiza uma genealogia na qual demarca quatro momentos áureos da luta das mulheres no país, com lutas protagonizadas sobretudo por ativistas e articuladoras provenientes das elites econômicas. A autora destaca I830 como ano no qual a bandeira do direito à alfabetização das mulheres é levantada, I870 como momento no qual a ênfase está na luta pela ampliação do direito à instrução e ao sufrágio universal, I920 como década em que os debates giram em torno da emancipação, da conquista do direito ao voto e da presença das mulheres na estruturação das primeiras organizações sindicais, sendo na década de I970 o momento no qual sobressaem temas como liberdade sexual, direitos reprodutivos, tendo destaque ainda a participação das mulheres na luta pela redemocratização do país. O texto é limitado, porém, pelo fato de não contemplar as lutas, nesses períodos, de mulheres indígenas e negras.

Ainda nessa seção, temos o artigo de Branca Moreira Alves, intitulado "A luta das sufragistas” (I980), no qual a autora, a partir do recurso à história comparada, traça as similaridades e distinções entre as lutas das sufragistas brasileiras e norte-americanas. É importante destacar que a década de I980 é um ambiente propício para as reflexões em torno da presença das mulheres na vida política do país devido aos debates e movimentos por redemocratização, somados à campanha pela Constituinte.

Esse debate é complementado, na mesma seção, pelo texto "A carta das mulheres brasileiras aos constituintes: memórias para o futuro" (2000), em que Jacqueline Pitanguy rememora as demandas e reinvindicações das brasileiras, nesse processo, sob a ótica do feminismo e dos direitos humanos.

A segunda seção, intitulada "Bandeiras tornam-se objeto de estudo", dedica-se à construção do campo dos estudos de gênero e dos estudos feministas e à relação mútua entre conhecimento acadêmico e luta política. Os artigos são dedicados a temas como violência, relações entre classe e gênero e o percurso do movimento feminista no país, com a presença de autoras como Heleieth Saffioti.

Já na seção "Interseccionalidades: pioneiras no feminismo brasileiro", destaca-se o papel de autoras como Lélia Gonzalez, Beatriz Nascimento e Sueli Carneiro nos debates sobre a desigualdade de gênero a partir da intersecção com outras desigualdades, sobretudo de raça e classe. No artigo "Racismo e sexismo na cultura 
brasileira” (1984), Lélia Gonzalez, dialoga com autores da psicanálise, como Fanon e Freud, para refletir sobre o racismo brasileiro e seus fundamentos nos ideais de democracia racial, por ela refutados. A autora apresenta o racismo como construção ideológica com benefícios sociais e econômicos para brancos de todas as classes sociais e destaca, a partir do estudo de fontes primárias ou das primeiras teorias sobre a sociedade brasileira, como a do sociólogo Gilberto Freyre, a construção narrativa da mulher negra como objeto sexual.

O capítulo conta ainda com dois artigos de Beatriz Nascimento: "A mulher negra no mercado de trabalho" (I976), dedicado às distinções entre mulheres brancas e negras no acesso às oportunidades profissionais, destacando-se o debate em torno do fator racial como causa das condições de subalternidade da mulher negra neste âmbito; e "A mulher negra e o amor" (I990), em que a autora retoma suas análises sobre o acesso e a circulação das mulheres negras no mercado de trabalho, criando correlações entre qualificação profissional e vida afetiva, para analisar os impactos dos padrões estéticos embranquecidos e do racismo na vida amorosa das mulheres negras.

Por fim, "Mulheres em movimento: contribuições do feminismo negro" (2003), de Sueli Carneiro, é o desejado contraponto aos demais artigos, que se propuseram a traçar uma história do feminismo no Brasil, sem que abarcassem, no entanto, o papel das militantes e pesquisadoras negras nas suas narrativas. Além de nos situar sobre a importância das militantes negras na construção do feminismo no país, a autora reflete sobre a relevância da sua luta na elaboração de políticas públicas afirmativas em diferentes campos, como saúde, educação e segurança.

Atendendo à hipótese levantada pela organizadora, na "Introdução", do pensamento feminista como uma epistemologia, a seção "Em busca de novos caminhos críticos" é tanto formada por artigos recentes, dedicados a analisar os impactos desses movimentos pioneiros na conquista de direitos políticos e sociais, como a Lei Maria da Penha, por exemplo, analisada por Lourdes Maria Bandeira no texto "Violência de gênero: a construção de um campo teórico e de investigação" (20II), como por artigos escritos no final da década de I990, marcando a transição de uma geração de feminismos, cujos retrospectos e emergências epistemológicas se fazem presente no artigo de Margareth Rago, intitulado "Epistemologia feminista, gênero e história" (I998), no qual a autora interpela a ciência e seus fundamentos, propondo que o feminismo é, mais do que um tema, um modo de pensar, conhecer e interpretar as relações sociais.

Ainda que pretenda mapear a emergência dos estudos de gênero e feministas no Brasil, o livro tem pesquisas majoritariamente realizadas e publicadas no Sudeste e, se são poucos os trabalhos que se dedicaram às realidades e problemas das outras regiões do país, são ainda mais raros aqueles enunciados a partir desses outros contextos. Nesse sentido, cabe problematizar que, para além das assimetrias de gênero, temos ainda que refletir sobre as assimetrias regionais, presentes nas circulação e distribuição do conhecimento feito por e sobre as mulheres.

Por fim se faz relevante destacar que Pensamento feminista brasileiro: formação $e$ contexto é, na prática, um livro-luta. Um livro que surge no momento do recrudescimento do projeto conservador no Brasil - projeto esse que tem como uma das suas principais características o retrocesso frente aos direitos e ao protagonismo 
das mulheres nesta sociedade. Nesse sentido, assim como a história que narra e sistematiza, a obra é a atualização da junção entre pesquisa acadêmica e militância. Um livro a partir do qual Heloisa Buarque de Hollanda reafirma sua posição de intelectual, professora e ativista, e que, somado aos outros livros organizados pela autora, constitui-se como uma rica e vasta contribuição para os estudos de gêneros e para a sistematização do pensamento feminista no país.

\section{SOBRE A AUTORA}

GLEYCE KELLY HEITOR é doutoranda em História Social da Cultura na Pontifícia Universidade Católica do Rio de Janeiro (PUC-Rio).

gkheitor@gmail.com

https://orcid.org/oooo-0oo2-6387-443X

\section{REFERÊNCIAS}

COTIDIANO. (I97I). Compositor e intérprete: Chico Buarque. In: BUARQUE, Chico. Construção. Phonogram/Philips. LP (I97I), CD (I988).

FEDERICI, Silvia. Calibã e a bruxa: mulheres, corpo e acumulação primitiva. São Paulo: Elefante, 20I7.

GROSFOGUEL, Ramón. The implications of subaltern epistemologies for global capitalism: transmodernity, border thinking and global coloniality. In: ROBINSON, William; APPLEBAUM, Richard (orgs.). Critical globalization studies. London: Routledge, 2005.

HOLLANDA, Heloisa Buarque de. [Entrevista concedida a] Antonio Herculano Lopes e Joëlle Rouchou, com a colaboração de Ana Pessoa e Beatriz Resende. Escritos - Revista da Fundação Casa de Rui Barbosa, ano 7, n. 7, 2013, p. 349-367.

HOLLANDA, Heloisa Buarque de. Explosão feminista: arte, cultura, política e universidade. São Paulo: Companhia das Letras, 2018.

HOLLANDA, Heloisa Buarque de (org.). Pensamento feminista: conceitos fundamentais. Rio de Janeiro: Bazar do Tempo, 2019.

RIBAS, Cristina. Vocabulário político para processos estéticos. Rio de Janeiro, 20I4. Disponível em: https:// vocabpol.cristinaribas.org/wp-content/uploads/20I5/oI/vocabpol_links-completo.pdf. Acesso em: $\mathrm{I}^{\mathrm{o}}$ set. 2020.

SLAM DAS MINAS. Manifesta. Disponível em: https://www.youtube.com/watch?v=xLJWFiGYNwo. Acesso em: Io set. 2020.

VOCÊ não entende nada. (I972). Compositor e intérprete: Caetano Veloso. In: VELOSO, Caetano. A arte de Caetano Veloso. Polygram/Philips, CD, I988.

WOOLF, Virginia. Profissões para mulheres e outros artigos feministas. Trad. Denise Bottmann. Porto Alegre: L\&PM, $20 I 2$. 